\title{
Assistentes sociais no sistema de saúde em Portugal: uma análise dos rácios ${ }^{1}$.
}

\section{Social workers in Portugal's healthcare system: a ratio analysis.}

\author{
Sónia Guadalupe* \\ Maria de Jesus Matos Gonçalves ** \\ Pedro Fonseca ${ }^{\star \star \star}$ \\ Ana Margarida Frias Furtado Silva ${ }^{* \star \star}$ \\ Olga Ávila ${ }^{* \star * *}$
}

\begin{abstract}
Resumo: $O$ artigo apresenta a dotação de assistentes sociais no sistema de saúde em Portugal, analisando os rácios para a população residente e a distribuição nos cuidados de saúde primários e hospitalares, discutindo as implicações na qualidade do sistema de saúde. Os resultados do estudo descritivo apontam a existência de 1032 assistentes sociais, dividindo-se sobretudo entre cuidados hospitalares $(52,4 \%)$ e cuidados primários $(42,9 \%)$. Os rácios determinam 1 assistente social para cada 10 mil habitantes, 1 para 23 mil habitantes nos cuidados primários e 1 para 65 camas hospitalares. Na equipa de saúde há assimetrias de 1 assistente social para cada 69,3 enfermeiros e 50,3 médicos. Conclui-se haver estagnação do contingente, desigual distribuição geográfica, e rácios desequilibrados face ao número de habitantes, utentes, unidades de saúde, camas hospitalares e outros profissionais. Tal condiciona a ação holística e de qualidade e limita a equidade de direitos do cidadão. A transversalidade e complexificação da intervenção na saúde não se compadecem com as
\end{abstract}

\footnotetext{
${ }^{1} \mathrm{O}$ rácio, do latim ratio, estabelece uma relação entre duas grandezas expressa por um coeficiente ou uma percentagem, sendo um indicador usado frequentemente para determinar a dotação de recursos humanos em determinadas áreas. No presente artigo, os rácios apresentados estabelecem uma relação entre o número de assistentes sociais no sistema de saúde e a população residente, as unidades de saúde e outros indicadores profissionais relevantes.

* Professora Auxiliar no Instituto Superior Miguel Torga (Coimbra, Portugal). Investigadora do CEISUC (Centre for Health Studies and Research of the University of Coimbra, Portugal). PhD em Serviço Social (2017, ISCTE-IUL, Lisbon), PhD em Saúde Mental (2009, University of Oporto), Mestre em Família e Sistemas Sociais (2000, ISMT), Licenciada em Serviço Social (1995, ISSSC). Assistente Social. Coordenadora da Licenciatura em Serviço Social do ISMT. Editora Chefe da Revista Portuguesa de Investigação Comportamental e Social. e-mail: soniaguadalupe@gmail.com

${ }^{* *}$ Assistente Social, ACeS Lisboa Ocidental e Oeiras, APSS - Grupo de Trabalho da Saúde, Portugal. E-mail: maria.j.goncalves@arslvt.min-saude.pt

*** Mestre em Serviço Social, Coordenador da Unidade de Ação Social do SESARAM, Ex-Presidente da Delegação Regional da Madeira da APSS, Portugal. E-mail: pedroscfonseca@gmail.com

**** Mestre em Serviço Social, Delegação Regional dos Açores da APSS, Portugal. E-mail: anamargaridafurtadosilva@ gmail.com

***** Assistente Social, APSS - Grupo de Trabalho da Saúde, Portugal. E-mail: olgafavila@gmail.com
} 
limitações evidenciadas, urgindo um reforço do grupo profissional de Serviço Social.

Palavras-chave: Serviço Social. Saúde. Rácios.

\begin{abstract}
The article presents the staff of social workers in Portugal's healthcare system, analyzing ratios due to the resident population and their distribution in primary and hospital care, discussing the implications for health system quality.

The results of the descriptive study indicate the existence of 1032 health social workers, mainly divided between hospital care (52.4\%), and primary care (42.9\%). The ratios determine 1 social worker for every 10,000 residents, 1 for 23,000 residents in community-based primary care, and 1 for 65 hospital beds. Within the health team, the asymmetries are evident, with 1 social worker for every 69.3 nurses and for every 50.3 doctors. Conclusions show the stagnation of health social workers, their unequal geographical distribution, and imbalanced ratios to the number of inhabitants, users, health units, hospital beds. and other professionals. This conditions a quality holistic approach and limits equal citizens' rights. The transversality and complexity of health intervention are not compatible with the highlighted limitations, urging the reinforcement of the Social Work professional group.
\end{abstract}

Key-words: Social Work. Healthcare. Staff Ratios.

Submetido em: 30/12/2019. Aceito em: 30/04/2020

\title{
INTRODUÇÃO
}

Os assistentes sociais trabalham na área da saúde há mais de 100 anos, tendo sido instituído em 1905 o primeiro Serviço Social hospitalar (Hospital Geral de Massachussets, EUA) (COWLES, 2012). À época, a passagem dos cuidados de saúde para o contexto de gabinete, afastando-os da tradição comunitária, restringiu a visão dos médicos acerca das condições do meio de vida do doente, entendendo-se, então, como necessária a integração de um profissional que trouxesse uma perspetiva complementar e compensatória da ação clínica (COWLES, 2012). Em Portugal o Serviço Social hospitalar seria institucionalizado na década de 1940, sendo os assistentes sociais integrados nos cuidados de saúde primários na década de 1970, aquando do seu processo de universalização (BRANCO; FARÇADAS, 2012; GUADALUPE, 2011). Na sua génese, os assistentes sociais na saúde assumiram, assim, as funções de elaboração do diagnóstico social, de apoio na adaptação do doente ao contexto hospitalar, na fase de recuperação e de reabilitação, a elaboração do processo de reintegração sociofamiliar e comunitária, estabelecendo uma estreita ligação entre os serviços de saúde, a família e os serviços sociais na comunidade.

Hoje os assistentes sociais inserem-se transversalmente nos diferentes níveis de cuidados de saúde (primários, hospitalares ou diferenciados, continuados e paliativos), assim como em várias áreas de especialidade, tais como: saúde materna, saúde infantil, intervenção precoce, saúde 
mental, oncologia, comportamentos aditivos e dependências (CAD), e reabilitação na diversidade funcional, deficiência e incapacidade (Figura 1).

Figura 1. Niveis de cuidados e áreas principais de inserção profissional dos assistentes sociais na saúde
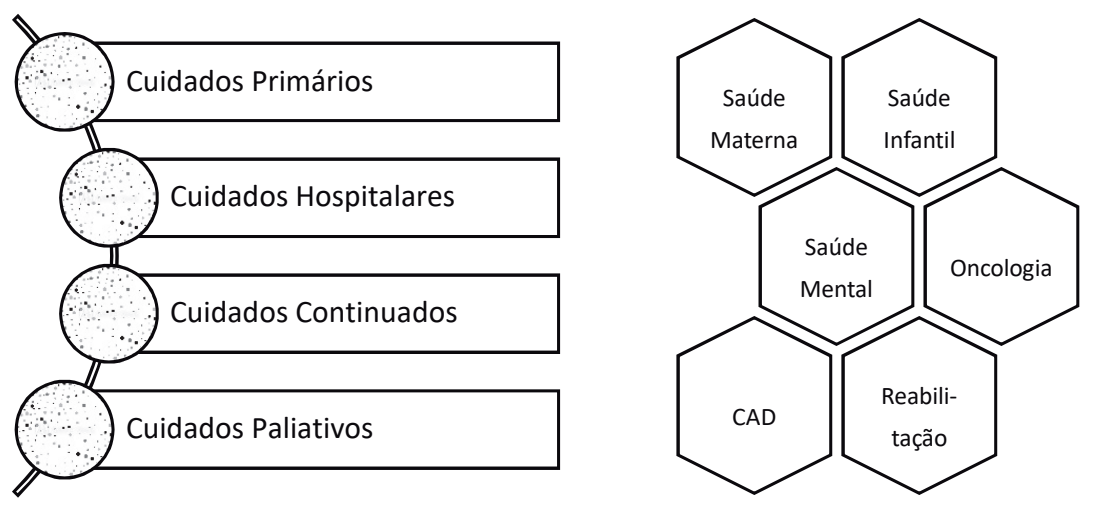

Fonte: Elaboração dos autores.

Os assistentes sociais constituem na atualidade profissionais-chave na intervenção nos diferentes níveis de cuidados e áreas. Porém, entende-se que a marca originária da sua complementaridade nem sempre os tem colocado na centralidade das equipas e dos serviços (GUADALUPE, 2012). Esta tendência para considerar o Serviço Social como complementar e não essencial nos serviços de saúde contraria os princípios do modelo holístico. Este modelo preconiza a visão da pessoa como um todo e das questões da saúde na sua complexidade, dependendo a sua abordagem de uma equipa de saúde multiprofissional e interdisciplinar.

Note-se que a fulcralidade do Serviço Social nesta área é reconhecida na legislação portuguesa desde meados do século XX, tendo introduzido a imprescindibilidade do diagnóstico social como complemento do clínico (Lei da Organização Hospitalar, Lei 2011/46 de 2 abril) e definido a natureza da ação dos estabelecimentos hospitalares como simultaneamente médica e social (Estatuto Hospitalar, Decreto-Lei n. 48357/68 de 27 de abril), tendo-se, a partir daí, institucionalizado o campo profissional. Todavia, na contemporaneidade registamos lacunas na consolidação do espaço profissional, apesar da relevância incontestada do Serviço Social na área da saúde (GUADALUPE, 2011). Se a nível hospitalar se verifica um elevado nível de integração funcional, já no contexto dos cuidados primários tem sido evidenciada uma baixa consagração das atribuições profissionais, com assimetrias de distribuição entre as unidades de saúde (BRANCO; FARÇADAS, 2012; GUADALUPE, 2011).

Se historicamente são reconhecidas múltiplas razões para a parca visibilidade do assistente social como ator profissional na área da saúde, há um crescente entendimento de como as necessidades sociais não atendidas prejudicam a saúde e produzem desigualdades, considerando-se o Serviço Social vital no esforço de conexão holística de domínios favorecedores do bem-estar social (RUTH; MARSHAL, 2017). Sabendo que todas as doenças são um fenómeno social "porque têm origens sociais, fatores sociais que influenciam a sua evolução e consequências, não somente para o indivíduo doente mas também para a sociedade" (MONDRAGÓN; TRIGUEROS, 1999, p. 16) e que as problemáticas das desigualdades sociais, da pobreza e da exclusão social estão correlacionadas com a saúde e a doença, sendo incontornáveis os determinantes sociais na sua abordagem (OMS-CDSS, 2010), exige-se uma intervenção em consonância com os patamares de conhecimento alcançados. 
Neste sentido, as condições sociais em que as pessoas vivem e trabalham, isto é, os fatores sociais, económicos, culturais, étnicos/raciais, psicológicos e comportamentais que influenciam os problemas e os riscos de saúde (OMS-CDSS, 2010), têm necessariamente de ser abordados transversalmente na área da saúde por profissionais qualificados para a sua avaliação e intervenção. Nesta conceção todo o Serviço Social é Serviço Social da saúde (BYWATERS; NAPIER, 2009), mas a exigência e complexidade da área da saúde determina especialização na intervenção.

Para garantir a qualidade da ação profissional e do acompanhamento dos utentes, é fundamental termos um referencial de racionalidade para o Serviço Social. Para os cuidados de saúde primários, no início dos anos oitenta, uma década cumprida após o início da sua universalização em Portugal, foram estabelecidos pelo Regulamento dos Centros de Saúde de $1983^{2}$ os rácios orientadores de 1 Assistente Social para cada 30 mil habitantes, não tendo mais sido atualizados em diplomas posteriores. Atualmente verificamos um vazio nos referenciais da racionalidade profissional em geral. Excecionalmente encontramos especificações de recursos humanos na área do Serviço Social no âmbito das Redes Nacionais de Cuidados Continuados Integrados e de Cuidados Paliativos (RNCCI e RNCP, respetivamente), assim como relativamente a áreas clínicas específicas. A RNCCI integra os assistentes sociais como recursos obrigatórios nas unidades de convalescença, unidades de média duração e reabilitação, unidades de longa duração e manutenção, equipas de gestão de altas a nível hospitalar e nas equipas domiciliárias ${ }^{3}$. A RNCP tem previstos rácios para os assistentes sociais enquanto membros das equipas das Unidades de Cuidados Paliativos, para as Equipas Intra-hospitalares de Suporte em Cuidados Paliativos e para as Equipas Comunitárias de Suporte em Cuidados Paliativos ${ }^{4}$ (SNS, 2017). Há ainda registo de regulamentação anterior que previa a definição de rácios na área hospitalar (sendo o racional com base no número de camas), assim como nas áreas da psiquiatria e na pediatria (estabelecendo-se o racional com base no número de equipas com médicos especialistas), mas que não se encontra em vigor.

Outras referências a rácios, a nível nacional e internacional, são encontradas de forma dispersa, disponíveis em legislação avulsa, regulamentos e em documentos institucionais, estipulando cálculos de número de casos (caseloads), tendo em conta a relação com o número de utentes internados e em ambulatório (in-patients e out-patients), e com a cobertura ou abrangência (social work coverage), encarando a relação com o território e com a acessibilidade ao Serviço Social (ZEBRACK, 2014). Tais dotações aparecem também referidas na literatura como workloads (isto é, cargas de trabalho atribuída à responsabilidade do profissional), baseadas no número de utentes afetos ou à população abrangida (respetivamente em case units ou population units), tendo em conta a referência à unidade de saúde ou à zona de abrangência do trabalho comunitário (LURIE, 1976), assim como aos standards de boas práticas que orientam a intervenção e o funcionamento de unidades de saúde.

A Organização Mundial de Saúde (WHO, 2006; DAL-POZ et al., 2007) considera que os assistentes sociais constituem recursos humanos da área da saúde que contribuem de forma vital para a saúde das populações. A mesma organização colocou na ordem do dia, no início da

\footnotetext{
${ }^{2}$ Artigo 70. ${ }^{\circ}$ do Despacho Normativo n. ${ }^{9}$ 97/83, de 22 de abril (Portugal).

${ }^{3}$ Portaria 174/2014 de 10 de setembro (Portugal) (artigos 16. e ANEXO IV - Recursos Humanos recomendados nas Unidades de Cuidados Continuados Integrados), indicando a seguinte afetação horária para o assistente social: Unidade de convalescença (40h); Unidades de média duração e reabilitação (40h); Unidades de longa duração e manutenção (40h); Unidade de dia e promoção da autonomia (20h). Portaria 50/2017 de 2 de fevereiro (artigos 16.ำ 7.ํ) (Portugal).

${ }^{4}$ As dotações previstas, respetivamente, são de: 1 assistente social - 0,55 tempo completo/12-20 camas; 1 assistente social - 0,3 tempo completo/250 utentes; 1 assistente social - 0,3 tempo completo/150 mil habitantes (SNS, 2017).
} 
presente década, a importância dos determinantes sociais da saúde, argumentando a relevância no investimento nas políticas sociais e na intervenção social junto das populações (OMS-CDSS, 2010; WHO, 2012), sendo fulcral o contributo dos assistentes sociais nestas esferas.

Considerando que o contingente profissional nos serviços sociais e de saúde constitui um forte indicador de desenvolvimento social, é nosso objetivo analisar os indicadores existentes sobre o número de assistentes sociais na área da saúde em Portugal e respetivos rácios, discutindo as suas implicações para o funcionamento e qualidade do sistema de saúde português, particularmente a nível do Serviço Nacional de Saúde.

\section{MATERIAL E MÉTODOS}

O estudo analisa a dotação de assistentes sociais no sistema de saúde português, caracterizando a sua distribuição no território nacional, e analisa os rácios que nos indicam a relação entre o número de profissionais, a população residente, as unidades de saúde e outros indicadores relevantes. Apresentamos um estudo descritivo sustentado em análise documental, que congrega quatro tipos de dados:

1. Dados oficiais acerca dos Assistentes Sociais em Portugal Continental e nas regiões de saúde cedidos pelo Instituto Público de Administração Central do Sistema de Saúde (ACSS) à Associação dos Profissionais de Serviço Social (APSS), de 2015 a 2017 (ACSS, 2017);

2. Dados dos assistentes sociais na região autónoma dos Açores cedidos pela Delegação Regional dos Açores da APSS, obtidos através de inquérito da organização profissional em 2016;

3. Dados dos assistentes sociais na Região Autónoma da Madeira cedidos pela Delegação Regional da Madeira da APSS, obtidos por levantamento em 2017;

4. Dados recolhidos junto do Serviço Social das oito Unidades Locais de Saúde existentes no SNS em Portugal Continental no sentido de obter dados desagregados relativos a assistentes sociais afetos aos cuidados de saúde primários e hospitalares.

A opção pelo uso de dados oficiais de 2017 relativos a Portugal Continental prende-se com a proximidade cronológica com os dados da APSS para as regiões autónomas (2016 e 2017, respetivamente). Os dados da população residente são também relativos ao ano de 2017 , referindo-se à média da população residente no período de 31-12-2016 a 31-12-2017. Note-se que os dados do número de assistentes sociais para Portugal Continental se têm mantido estáveis nos anos mais recentes (ACSS, 2017).

Os dados disponíveis para Portugal Continental restringem-se à administração pública, excluindo-se os assistentes sociais em exercício em unidades de saúde privadas ou em instituições do sector solidário (instituições particulares de solidariedade social, ou com outra natureza jurídica) vocacionadas para os cuidados de saúde. Já os dados das regiões autónomas são globais, abrangendo não apenas as entidades públicas, atendendo às idiossincrasias da administração regional. Apesar das limitações e do desfasamento cronológico dos dados (2016-2017), consideramos existirem vantagens na sua incorporação. Os dados relativos às regiões autónomas foram obtidos 
com o consentimento informado dos assistentes sociais, tendo sido fornecidos aos autores do estudo de forma anónima, tendo sido eliminados os dados de identificação pessoal.

Depois de agregados os dados, estes foram analisados tendo em conta estatísticas nacionais disponibilizadas pelo Instituto Nacional de Estatística (INE) e pela Base de Dados Portugal Contemporâneo da Fundação Francisco Manuel dos Santos (Pordata).

\section{RESULTADOS}

A distribuição territorial dos assistentes sociais na área da saúde em Portugal mostra-nos que estes se concentram fundamentalmente na região de Lisboa e Vale do Tejo $(33,7 \%)$ e no Norte $(31,8 \%)$, sendo mais residual a sua representatividade nas restantes regiões, registando-se o menor contingente relativo nos Açores (Tabela 1). Note-se que os serviços centrais (IPST - Instituto Português do Sangue e Transplantação; SICAD - Serviço de Intervenção nos Comportamentos Aditivos e nas Dependências) integram 1,2\% $(n=12)$ dos assistentes sociais. Apesar de estes poderem estar localizados em diversas zonas geográficas, na presente análise foram enquadrados na região de Lisboa e Vale do Tejo, onde se situam outros serviços centrais, fazendo subir esta região de $336(32,6 \%)$ assistentes sociais para $348(33,7 \%)$.

Tabela 1. Número de Assistentes Sociais na área da saúde em Portugal

\begin{tabular}{|c|c|c|}
\hline & $n$ & $\%$ \\
\hline Portugal Continental (a) & 980 & - \\
\hline Norte & 328 & 31,8 \\
\hline Centro & 204 & 19,8 \\
\hline Lisboa e Vale do Tejo & $348^{(\mathrm{c})}$ & 33,7 \\
\hline Alentejo & 55 & 5,3 \\
\hline Algarve & 45 & 4,4 \\
\hline Região Autónoma dos Açores ${ }^{(b)}$ & 21 & 2,0 \\
\hline Região Autónoma da Madeira ${ }^{(a)}$ & 31 & 3,0 \\
\hline PORTUGAL & 1032 & $100 \%$ \\
\hline
\end{tabular}

Fontes: ACSS (Dados de Portugal Continental e Regiões de Saúde); APSS - Delegação Regional dos Açores (Dados da Região Autónoma dos Açores); APSS - Delegação Regional da Madeira (Dados da Região Autónoma da Madeira). Tabela elaborada pelos autores.

(a) Dados de 2017.

(b) Dados de 2016.

(c) inclui 12 assistentes sociais Serviços Centrais: IPST, SICAD.

Apesar das limitações da utilização de rácios de base populacional, procedemos ao seu cálculo tendo em consideração que a legislação portuguesa fez referência, no passado, ao uso de rácios desta natureza.

Assim, o rácio de assistente social para a população residente em Portugal é de 1 para cada cerca de 10 mil habitantes, variando entre 1 para cerca de 8 mil e 1 para cerca de 13 mil residentes. O Alentejo é a região que apresenta o rácio mais baixo, sendo Lisboa e a Madeira as regiões que apresentam o mais elevado. Existem cerca de 10 assistentes sociais para cada 100 mil residentes em Portugal, com variações regionais assinaláveis (Tabela 2). 
Tabela 2. Rácios de Assistentes Sociais para a População Residente em Portugal

\begin{tabular}{lllll}
\hline & $n$ & $\begin{array}{l}\text { População } \\
\text { residented }\end{array}$ & Rácio & $\begin{array}{l}\text { AS por cada 100 } \\
\text { mil residentes }\end{array}$ \\
\hline Portugal Continental & $980^{(\mathbf{b})}$ & 9801106 & $1: 10001,13$ & 10,00 \\
\hline Norte & 328 & 3580390 & $1: 10915,82$ & 9,16 \\
\hline Centro & 204 & 2237640 & $1: 10968,82$ & 9,12 \\
\hline Lisboa e Vale do Tejo & $348^{(b)}$ & 2827514 & $1: 08125,04$ & 12,31 \\
\hline Alentejo & 55 & 715019 & $1: 13000,35$ & 7,69 \\
\hline Algarve & 45 & 440543 & $1: 09789,84$ & 10,21 \\
\hline Região Autónoma dos Açores & 21 & 244573 & $1: 11646,33$ & 8,59 \\
\hline Região Autónoma da Madeira & 31 & 254622 & $1: 08213,61$ & 12,17 \\
\hline PORTUGAL & 1032 & 10300300 & $1: 09980,91$ & 10,02 \\
\hline
\end{tabular}

Notas: Dados de Assistentes Sociais de 2016 e 2017 - Fontes: ACSS (Dados de Portugal Continental e Regiões de Saúde); APSS - Delegação Regional dos Açores (Dados da Região Autónoma dos Açores); APSS - Delegação Regional da Madeira (Dados da Região Autónoma da Madeira). Tabela elaborada pelos autores.

(a) População residente, estimativas anuais para 2017 a meio do ano civil (INE, Pordata): NUTS I: 10.300.300 residentes.

(b) Inclui 12 assistentes sociais Serviços Centrais: IPST, SICAD.

AS - Assistente Social

o Gráfico (Figura 2) representa a parca variação do número de profissionais de Serviço Social em Portugal Continental, tendo-se registado um ligeiro incremento de 4,14\% entre 2015 e 1017, ainda que entre 2016 e 2017 tenha sido apenas de $0,62 \%$ o que aponta para uma tendente estagnação dos recursos humanos nesta área.

Figura 2. Evolução do Número de Assistentes Sociais na Saúde de 2015 a 2017 em Portugal Continental $2015 \square 2016 \square 2017$

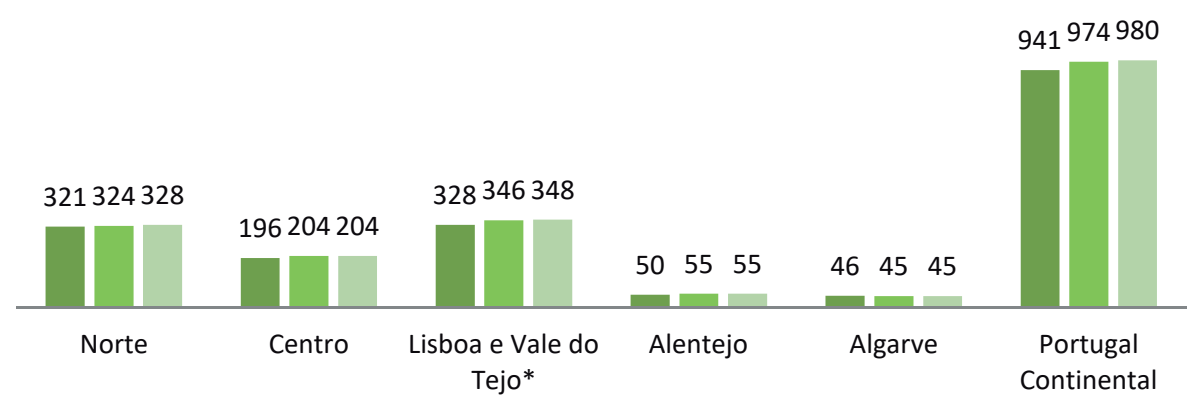

Fonte: ACSS (abril, 2017) ～" Inclui os Serviços Centrais (IPST, SICAD): $n=14$ (2015); 12 (2016); 12 (2017).

Fonte: Elaboração dos Autores.

Quanto às características sociodemográficas, o grupo profissional é maioritariamente do sexo feminino (94,5\%) e apresenta uma média de idades de aproximadamente 45 anos, variando entre uma média etária de 37,6 e de 49,2 anos, sendo claramente o grupo profissional mais jovem nos Açores e mais envelhecido na região Centro e nos serviços centrais (Tabela 3). 
Tabela 3. Idade e Sexo dos Assistentes Sociais na área da Saúde em Portugal

\begin{tabular}{lccccc}
\hline & Média de idades & \multicolumn{2}{l}{ Sexo Feminino } & \multicolumn{2}{c}{ Sexo Masculino } \\
\hline & $M$ & $n$ & $\%$ & $n$ & $\%$ \\
\hline Portugal Continental & & & & & \\
\hline Norte & 46,7 & 307 & 93,6 & 21 & 6,4 \\
\hline Centro & 49,2 & 188 & 92,2 & 16 & 7,8 \\
\hline Lisboa e Vale do Tejo & 43,6 & 325 & 96,7 & 11 & 3,3 \\
\hline Alentejo & 44,9 & 52 & 94,5 & 3 & 5,5 \\
\hline Algarve & 43,7 & 43 & 95,6 & 2 & 4,4 \\
\hline Serviços Centrais ${ }^{\text {(a) }}$ & 49,0 & 12 & 100,0 & 0 & 0,0 \\
\hline Região Autónoma da Madeira & 45,0 & 28 & 90,3 & 3 & 9,7 \\
\hline Região Autónoma dos Açores & 37,6 & 20 & 95,2 & 1 & 4,8 \\
\hline PORTUGAL & 44,9 & 975 & 94,5 & 57 & 5,5 \\
\hline
\end{tabular}

Notas: Dados de Assistentes Sociais de 2016 e 2017 - Fontes: ACSS (Dados de Portugal Continental e Regiões de Saúde); APSS - Delegação Regional dos Açores (Dados da Região Autónoma dos Açores); APSS - Delegação Regional da Madeira (Dados da Região Autónoma da Madeira). Tabela elaborada pelos autores.

(a) Neste caso os dados dos Serviços Centrais (IPST, SICAD) estão separados da região de Lisboa e Vale do Tejo, por termos acesso aos dados finais e não aos dados brutos.

O contingente de assistentes sociais divide-se sobretudo entre os cuidados primários $(42,9 \%)$ e os cuidados hospitalares (52,4\%) (Tabela 4$)$.

Tabela 4. Número de Assistentes Sociais por principais áreas de cuidados de saúde

\begin{tabular}{lll}
\hline Área & $n$ & $\%$ \\
\hline Cuidados Hospitalares $^{(\mathrm{b})}$ & 541 & 52,4 \\
\hline Cuidados Primários $^{(a)}$ & 443 & 42,9 \\
\hline Outra $^{(\mathrm{c})}$ & 48 & 4,7 \\
\hline Total & 1032 & 100 \\
\hline
\end{tabular}

Notas: Dados de Assistentes Sociais de 2016 e 2017. Fontes: ACSS (Dados de Portugal Continental); APSS - Delegação Regional dos Açores (Dados da Região Autónoma dos Açores); APSS - Delegação Regional da Madeira (Dados da Região Autónoma da Madeira). Tabela elaborada pelos autores.

(a) Inclui 2 tipos de Entidades: Hospitais e Unidades Locais de Saúde.

(b) Inclui 2 tipos de Entidades: Administrações Regionais de Saúde e Unidades Locais de Saúde.

(c) Inclui os serviços centrais (IPST, SICAD) e, no caso das regiões autónomas, a área da saúde mental, dependências e outras; inclui assistentes sociais das Unidades Locais de Saúde não integrados em hospitais ou centros de saúde (Fonte: ACSS, 2017); não dispomos de dados desagregados para Portugal Continental.

Dado que os cuidados de saúde primários são de base territorial, desagregámos os dados de assistentes sociais afetos a este nível de cuidados e calculámos os rácios para a população residente, no seu total e segmentada em grandes grupos etários (Tabela 5). Nos cuidados de saúde primários verifica-se a existência de 1 assistente social para cada cerca de 23 mil residentes. Tendo em consideração a segmentação etária, aponta-se a existência de 1 profissional para cada 3.235 crianças e jovens, 15.061 adultos e 4.955 idosos. 
Tabela 5. Rácios de Assistentes Sociais para a População Residente em Portugal por grandes grupos etários: dados gerais e nos cuidados de saúde primários

\begin{tabular}{llll}
\hline & & $\begin{array}{l}\text { Rácio de Assistentes } \\
\text { sociais em Portugal }\end{array}$ & $\begin{array}{l}\text { Rácio de Assistentes } \\
\text { sociais nos CSP }\end{array}$ \\
\hline & $n$ & $N=1032$ & $N=443$ \\
\hline População residente em Portugal & 10300300 & $1: 9980,9$ & $1: 23251,2$ \\
\hline $\begin{array}{l}\text { População residente jovem } \\
\text { 0-14 anos }\end{array}$ & 1433156 & $1: 1388,7$ & $1: 3235,1$ \\
\hline $\begin{array}{l}\text { População residente adulta } \\
\text { 15-64 anos }\end{array}$ & 6672187 & $1: 6465,3$ & $1: 15061,4$ \\
\hline $\begin{array}{l}\text { População residente idosa } \\
\text { 65+ anos }\end{array}$ & 2194957 & $1: 2126,90$ & $1: 4954,8$ \\
\hline
\end{tabular}

Notas: Dados de Assistentes Sociais de 2016 e 2017 - Fontes: ACSS (Dados de Portugal Continental e Regiões de Saúde); APSS - Delegação Regional dos Açores (Dados da Região Autónoma dos Açores); APSS - Delegação Regional da Madeira (Dados da Região Autónoma da Madeira): 1032 assistentes sociais. Tabela elaborada pelos autores.

População residente por grandes grupos etários para 2017 a meio do ano civil (INE, Pordata): NUTS I: 10.300.300 residentes.

CSP - Cuidados de Saúde Primários.

Apesar de não termos dados da distribuição efetiva dos assistentes sociais pelos Agrupamentos de Centros de Saúde e unidades funcionais nos cuidados primários, a análise do número de assistente sociais nos cuidados de saúde primários permite estimar a inserção de cerca de 8 assistentes sociais por cada ACeS, havendo 1,3 centros de saúde por cada profissional (Tabela 6).

Tabela 6. Estimativa de Assistentes Sociais nos cuidados de saúde primários

\begin{tabular}{lll}
\hline & $\mathrm{n}$ & \multicolumn{1}{l}{ Rácios } \\
\hline Assistentes Sociais nos cuidados primários em Portugal & 443 & - \\
\hline $\begin{array}{l}\text { Assistentes Sociais nos cuidados primários em Portugal } \\
\text { Continental }\end{array}$ & 426 & - \\
\hline $\begin{array}{l}\text { Agrupamento de Centros de Saúde (ACeS) / Unidade de Recursos } \\
\text { Assistenciais Partilhados (URAP) em Portugal Continental (a) }\end{array}$ & 55 & 7,7 AS : ACeS/URAP \\
\hline $\begin{array}{l}\text { Centros de saúde em Portugal Continental } \\
\text { (b) }\end{array}$ & 388 & $\begin{array}{l}\text { 1,1 AS : centro de } \\
\text { saúde }\end{array}$ \\
\hline $\begin{array}{l}\text { População inscrita nos CSP(c) } \\
\text { Estimativa de Utentes em Consultas Médicas pelos Inscritos nos } \\
\text { ACeS }^{(d)}\end{array}$ & 7031357 & 1 AS / 16 505,5 \\
\hline
\end{tabular}

Notas: No cálculo dos rácios é usado o número de assistentes sociais para Portugal ou Portugal Continental quando os dados são relativos a Portugal (Portugal Continental e Regiões Autónomas) ou Portugal Continental, respetivamente. Tabela elaborada pelos autores.

(a) Fonte: ACSS

(b) Fonte: INE, Pordata, DGS/MS (DGS, 2014) - dados de 2011 para Portugal Continental.

(c) Fonte: SNS - Portal da Transparência. Dados calculados para janeiro de 2017 com base no número de utentes inscritos por ACeS (Portugal Continental).

(d) Fonte: SNS - Portal da Transparência. Dados calculados a partir da Taxa de Utilização Consultas Médicas 1 Ano (Todos os Utentes inscritos nos ACeS em Portugal Continental). Taxa média estimada para dados de janeiro de 2017: 70,14 (Total de utentes: 10024747).

AS - Assistente Social; SNS - Serviço Nacional de Saúde. 
Apesar dos diferentes níveis de diferenciação hospitalar e das diferentes dimensões de cada unidade, estimamos que a disponibilidade de recursos humanos na área do Serviço Social na rede de hospitais em todo o sistema de saúde em Portugal seja de 2 para cada unidade hospitalar, subindo para cerca de 5 para cada hospital do SNS. Baseando-nos no número de camas, consultas, internamentos e urgências hospitalares estimadas para 2017, fazemos notar que se registam aproximadamente 36 mil consultas, mais de 2100 internamentos e mais de 14 mil urgências por cada assistente social existente nos cuidados hospitalares, estimando-se que existam 65 camas ou 43 camas por cada profissional na totalidade dos hospitais ou nos hospitais do SNS, respetivamente (Tabela 7).

Tabela 7. Estimativa de Assistentes Sociais nos hospitais por número unidades, camas, consultas, internamentos e urgências hospitalares

\begin{tabular}{lll}
\hline & $\mathrm{n}$ & Rácios \\
\hline Assistentes Sociais nos hospitais em Portugal & 541 & - \\
\hline $\begin{array}{l}\text { Assistentes Sociais nos hospitais em Portugal } \\
\text { Continental }\end{array}$ & 520 & - \\
\hline $\begin{array}{l}\text { Hospitais do SNS - Portugal Continental (a) } \\
\text { Camas hospitalares no SNS - Portugal Continental }^{(\mathrm{a})}\end{array}$ & 99 & 5,3 AS / hospital \\
\hline Unidades hospitalares oficiais (públicos e privados) $^{(\mathrm{b})}$ & 225 & 42,5 camas / AS \\
\hline Camas hospitalares nas unidades hospitalares oficiais $^{(\mathrm{b})}$ & 34953 & 2,4 AS / hospital \\
\hline Consultas hospitalares $^{(\mathrm{c})}$ & 19780600 & 64,6 camas / AS \\
\hline Internamentos $^{(\mathrm{c})}$ & 1158600 & 2142 internamentos / 1 AS \\
\hline Urgências $^{(\mathrm{c})}$ & 7641900 & 14126 urgências / 1 AS \\
\hline
\end{tabular}

Notas: No cálculo dos rácios é usado o número de assistentes sociais para Portugal ou Portugal Continental quando os dados são relativos a Portugal (Portugal Continental e Regiões Autónomas) ou Portugal Continental, respetivamente. Tabela elaborada pelos autores.

(a) Fonte: INE, Pordata dados de 2017. Inclui os hospitais gerais $(n=77)$ e especializados $(n=22)$ do SNS em Portugal Continental.

(b) Fonte: INE, Pordata dados de 2017. Refere-se a unidades hospitalares oficiais, públicas e não públicas, ou privadas.

(c) Fontes: INE, Pordata, DGS/MS (SNS, 2017) - dados de 2017.

Tendo em consideração a relevância do trabalho em equipa na área saúde, onde se destacam grupos profissionais como os médicos e os enfermeiros, analisamos comparativamente os rácios de assistentes sociais, médicos e enfermeiros para a população residente em Portugal, sendo a relação para os enfermeiros de $-98,6 \%$ e para os médicos de $-98 \%$. Existe um assistente social na área da saúde para cada 69,3 enfermeiros e para cada 50,3 médicos (Tabela 8). 
Tabela 8. Assistentes Sociais e outros profissionais da saúde: Rácios para a população residente em Portugal e rácios entre profissionais

\begin{tabular}{lll}
\hline & $\mathrm{n}$ & Rácio \\
\hline Rácios de profissionais para a população residente em 2017 & & \\
\hline Assistente Social & 1032 & $1: 9980,9$ \\
\hline Médico & 51937 & $1: 198,3$ \\
\hline Enfermeiro & 71578 & $1: 143,9$ \\
\hline
\end{tabular}

Rácios de médico e enfermeiro para cada Assistente Social em 2017

\begin{tabular}{llc}
\hline Médico & 51937 & $1: 50,3$ \\
\hline Enfermeiro & 71578 & $1: 69,3$ \\
\hline
\end{tabular}

Fontes: INE, Pordata dados para 2017 - Número de habitantes por médico e por outro pessoal de saúde; Número de médicos e enfermeiros. População residente em 2017 a meio do ano civil: NUTS I: 10.300.300 residentes. Tabela elaborada pelos autores.

Dados de Assistentes Sociais de 2016 e 2017 - Fontes: ACSS (Dados de Portugal Continental e Regiões de Saúde); APSS Delegação Regional dos Açores (Dados da Região Autónoma dos Açores); APSS - Delegação Regional da Madeira (Dados da Região Autónoma da Madeira): 1032 profissionais.

\section{DISCUSSÃO}

O exercício apresentado no presente estudo não pode ser lido nem interpretado linearmente. 0 cálculo de rácios com base no número de assistentes sociais na área da saúde em Portugal em função dos indicadores analisados (populacionais, regionais, de níveis de cuidados e por tipo entidade, de recursos humanos, de produtividade e outros), apresenta um conjunto de limitações que analisaremos, ainda que nos garanta pistas pertinentes para reflexão. Assim, discutiremos as implicações dos resultados para o funcionamento e para a qualidade do sistema de saúde português, especificamente a nível do Serviço Nacional de Saúde, que completou 40 anos a 15 de setembro de 2019.

Consultando os dados sobre a População residente em Portugal entre 2015 e 2017, ainda que tendencialmente decrescente, a variação do número de habitantes apresenta um valor insignificante, permitindo reter a nossa análise sobre a variação do número de profissionais em exercício em Portugal e o rácio calculado em função da população residente.

Parece evidente que a existência de 1 assistente social na área da saúde por cada cerca de 10 mil habitantes tenderá a limitar a participação destes profissionais nos objetivos gerais de promover, prevenir, recuperar e reabilitar a saúde. Assinala-se, por isso, com preocupação o parco investimento no aumento destes recursos humanos, tendo-se registado apenas um ligeiro incremento de 4,14\% no seu número entre os anos de 2015 e 1017, em Portugal Continental. A estagnação do número de assistentes sociais parece associar-se à falta de renovação destes recursos humanos, que poderá deduzir-se atendendo à média etária apresentada (cerca de 45 anos de idade). Ainda que só tenhamos tido acesso às médias das idades (sem dados relativos à dispersão e amplitude na variação), é de notar que tais médias, na maior parte das regiões, colocam os profissionais na segunda metade de desenvolvimento das suas carreiras. A continuar a estagnação verificada nos últimos anos, assistiremos a um envelhecimento crescente dos recursos humanos nesta área e eventualmente à diminuição do contingente, atendendo a um potencial 
desequilíbrio entre aposentação e recrutamento. Esta é uma situação marcada pelas constantes medidas de restrição de acesso à função pública nas últimas décadas, agudizadas pelas políticas de austeridade que vigoraram recentemente no país que continuam a condicionar a admissão e a progressão nas carreiras na administração pública. Os entraves à contratação e à vinculação à função pública deixam adivinhar a dificuldade de crescimento e de renovação desta categoria profissional no âmbito do SNS. Acrescentam-se os entraves à realização de estágios profissionais por parte das entidades administradoras do SNS, que também condicionam a qualificação de futuros profissionais.

Apesar do interesse da análise de rácios populacionais, esta apresenta limitações a considerar, desde logo porque não dá conta das desigualdades territoriais, da morfologia do território, dos acessos desiguais, da interioridade, da insularidade, assim como das variações demográficas, das transições epidemiológicas e das diferenças nas condições de vida da população nos diferentes territórios.

Dos resultados, ressalta a desigual distribuição dos assistentes sociais na área da saúde pelo país, tendo em conta as regiões de saúde, o que pode colocar em causa a equidade de direitos nos cuidados ao cidadão. Esta distribuição estará associada à cobertura da rede de serviços e à densidade populacional, assumindo o país iniquidades entre o litoral e o interior, sendo nas zonas litorais onde se concentram mais recursos humanos, particularmente na capital (SANTANA, 2014; OECD; EC, 2016).

Os 980 assistentes sociais no SNS estão integrados na carreira de Técnico Superior do Regime Geral, que reporta a um universo de 4.100 profissionais, representando, assim, $24 \%$ do universo de Técnicos Superiores do SNS (ACSS, 2017), ascendendo a 1032 quando adicionamos os assistentes sociais na área da saúde nas Regiões Autónomas da Madeira e dos Açores.

Tendo em consideração os dados analisados relativamente aos níveis de cuidados de saúde, os assistentes sociais dividem-se sobretudo entre os cuidados hospitalares $(52,4 \%)$ e os cuidados primários (42,9\%). Os dados disponíveis não permitem uma análise que considere outros níveis de cuidados, não contemplando de forma integral os cuidados continuados e os cuidados paliativos ${ }^{5}$.

Atendendo a que os cuidados de saúde primários são de base territorial e comunitária, é relevante fazer a análise do racional de assistentes sociais nesta área por população residente.

Nos cuidados de saúde primários verifica-se a existência de 1 assistente social para cada cerca de 23 mil residentes. Tendo em consideração a segmentação etária, aponta-se a existência de 1 profissional para cada 3200 crianças e jovens, 15000 adultos e 4900 idosos, aproximadamente. Fazendo jus à universalidade dos cuidados de saúde primários, o número de utentes inscritos nos ACeS é muito semelhante ao número de residentes, podendo aferir-se estes rácios como indicadores relevantes, ainda que possam não corresponder ao verificado em cada ACeS, em concreto, atendendo a não dispormos de dados desagregados, o que impede a análise da distribuição efetiva dos assistentes sociais pelos ACeS e unidades funcionais nos cuidados primários. No entanto, sublinhamos que se estima a inserção de cerca de 8 assistentes sociais por cada ACeS,

\footnotetext{
${ }^{5}$ Não dispomos neste estudo de dados completos das entidades da Rede Nacional de Cuidados Continuados Integrados (RNCCI) e da Rede Nacional de Cuidados Paliativos (RNCP) que não integram o SNS, pelo que apenas temos dados de parte dos assistentes sociais inseridos nestes níveis de cuidados (isto é, das Equipas de Cuidados Integrados, Equipas Comunitárias de Suporte em Cuidados Paliativos e Equipas Intra-hospitalares de Suporte em Cuidados Paliativos, que integram assistentes socias dos cuidados primários e dos hospitais). Atente-se que das 677 entidades com respostas contratadas no âmbito da RNCCI, apenas 43,6\% reportam juridicamente ao SNS (In ACSS http://www.acss.min-saude.pt/).
} 
havendo 1,1 por cada centro de saúde e 0,35 por cada extensão ${ }^{6}$. Sabendo-se que nem todos os profissionais do universo aqui considerado estão integrados diretamente em centros de saúde (pois parte dos recursos humanos estão alocados às ARS e aos DICAD, por exemplo), o racional estimado seria diferente, diminuindo o número de assistentes socias por ACeS e aumentando o número de centros de saúde para cada profissional.

Em 1983, numa fase de evolução dos chamados centros de saúde de primeira geração, definia-se o racional profissional de 1 para cada 30 mil habitantes, nunca tendo sido este racional cumprido ou revisto em função das novas funções que foram sendo atribuídas aos assistentes sociais nos cuidados de saúde primários, especialmente desde o início do século XXI.

Num estudo anterior desenvolvido sobre a Região Centro do país (no âmbito da área abrangida pela Administração Regional de Saúde do Centro), que analisou os rácios de assistentes sociais por número de unidades, extensões e população inscrita por unidade de saúde, verificou-se que existiam 49 assistentes sociais e um total de 109 centros de saúde (GUADALUPE; GONÇALVES, 2009). Destes, 47 estavam cobertos por 1 Assistente Social, abrangendo 65\% dos utentes inscritos na região; já 62 centros de saúde, que abrangiam 35\% dos utentes, não apresentavam estes profissionais nos seus quadros. Se nalguns concelhos o rácio por população inscrita era de 1 assistente social para cerca de 24 mil habitantes, já noutros a população inscrita os rácios eram de 1 profissional para 56 mil e 58 mil utentes, isto é, quase o dobro do que estava previsto na lei (30 mil) (GUADALUPE; GONÇALVES, 2009) e quase o triplo do que era recomendado pela OMS (20 mil) (GEPS, 1979).

O rácio médio que encontramos atualmente é melhor (1 profissional para cerca de 23 mil cidadãos residentes / inscritos em cuidados primários), mas pode esconder assimetrias relevantes na distribuição e cobertura que deverão ser exploradas em futuras pesquisas. No entanto, já num documento de trabalho de 1979 do Gabinete de Estudos e Planeamento da Secretaria de Estado da Saúde portuguesa, ano de criação do Serviço Nacional de Saúde, divulgado numa publicação da APSS (Cadernos, n. 6, 1979) sobre o Serviço Social no Sector da Saúde (GEPS, 1979), se indicava que as orientações da OMS de assistentes sociais por habitantes era de 1 para cada 20 mil. Considerava-se que a desproporção que se verificava na altura era comprometedora de uma intervenção correta do Serviço Social, apelando-se a que houvesse investimento na sua correção, indo ao encontro dos parâmetros internacionais, o que não veio a espelhar-se na legislação publicada após esta recomendação, em 1983. Aparentemente, o alinhamento mais aproximado com os rácios indicados na década de 1970 pela OMS surge passados cerca de 50 anos, sendo atualmente deficitários atendendo às transformações societais entretanto ocorridas e à acrescida exigência de qualidade de serviços que se preconiza na contemporaneidade.

Apesar do racional ser hoje geralmente melhor do que há uma década, não permite ainda uma intervenção com a transversalidade e a qualidade desejáveis, numa perspetiva holística. Registando-se 1,1 assistentes sociais para cada centro de saúde, levando a um "Serviço Social unipessoal”, tal bloqueia a afirmação da jurisdição profissional neste campo de trabalho (BRANCO; FARÇADAS, 2011, p. 17). Neste quadro, o assistente social tende a uma intervenção pragmático-imediatista, privilegiando o atendimento aos utentes, numa dimensão assistencial e relacional, centrado na promoção do seu acesso à saúde (BRANCO; FARÇADAS, 2011), não sendo garantidas

\footnotetext{
${ }^{6}$ Em 2011 existiam 1199 extensões de centros de saúde em Portugal Continental, que são unidades periféricas dos Centros de Saúde, situadas em local da sua zona geográfica de influência, que proporcionam uma maior proximidade e acessibilidade dos utentes (Fonte: INE, DGS/MS, Pordata, dados de 2011 para Portugal Continental).
} 
condições para o seguimento e reavaliação das situações atendidas e para uma intervenção mais efetiva noutras áreas.

A baixa densidade de assistentes sociais nos cuidados primários tem afetado a visibilidade, o reconhecimento e a eficácia do seu trabalho (APSS, 2017, p. 2), pois estes são convocados a participar em vários programas e equipas de saúde e comissões na comunidade, o que potencia uma enorme dispersão, sobreposição e acumulação de funções. Os assistentes sociais, integrados nas Unidades de Recursos Assistenciais Partilhados dos ACeS, participam atualmente na área da saúde familiar, através do apoio prestado aos utentes inscritos nas Unidades de Saúde Familiar e nas Unidades de Cuidados de Saúde Personalizados, na área da saúde comunitária, participando nas equipas multiprofissionais de Cuidados Continuados Integrados (ECCI), de Cuidados Paliativos (ECSCP) e da promoção da parentalidade, e na área da saúde pública, integrando as equipas de Saúde Escolar, dos Núcleos de Apoio à Criança e Jovem em Riscos (NACJR), as Equipas de Prevenção da Violência no Adulto (EPVA) e as Equipas Locais de Intervenção Precoce (ELI/ SNIPI). Para além disso, asseguram também os Gabinetes do Cidadão, e representam os ACeS nos programas parceria obrigatória, tais como, a Rede Social, as Comissões de Proteção a Crianças e Jovens (CPCJ) e o Rendimento Social de Inserção (RSI) e outros projetos de âmbito local. Assim, o racional verificado obriga a uma exigente organização do trabalho e do tempo, mas nem sempre evita que seja prejudicada a participação nos programas comunitários de promoção da saúde e de prevenção, ou que haja demora nos processos de avaliação e de referenciação para recursos comunitários que dão resposta desde a infância à idade avançada, afetando a qualidade dos serviços prestados ao cidadão. Neste contexto, a mediação e o trabalho em rede, característicos da ação profissional, transmutam-se em articulações qualificadas pontuais, não permitindo alcançar níveis de sistematização que confiram maior eficácia às intervenções que dependem destas estratégias profissionais.

Sendo eminentemente um serviço assegurado por um só profissional, facilmente equacionamos que são interrompidos ou adiados os serviços aos cidadãos quando há uma situação de incapacidade temporária para o trabalho ou quando há férias programadas por parte do único assistente social na unidade de saúde. A área dos cuidados de saúde primários é uma área de primazia para a intervenção dos assistentes sociais, pelo que Guadalupe \& Gonçalves (2009) defendem a criação do "Assistente Social de Família”. O eventual desafio de criar este novo perfil profissional de referência, assim como de integrar novas funções face aos desafios da saúde comunitária, exigiria aumentar substancialmente o número de profissionais nos cuidados primários, aumentando potencialmente os ganhos em saúde e em coesão social.

A crescente amplitude e complexificação do campo de intervenção do Serviço Social nas unidades de saúde não se compadece com as limitações de recursos humanos que verificamos nos cuidados de saúde primários, condicionando o desenvolvimento de programas de ação junto da população, redundando no risco de uma abordagem individualizada e casuística (BRANCO; FARÇADAS, 2011), e numa intervenção com resposta limitada face às necessidades dos utentes e da comunidade. Rácios profissionais pouco adequados potenciam também obstruções indesejáveis entre o serviço social nos diferentes níveis de cuidados.

Já no âmbito dos cuidados hospitalares, o crescente consumo de cuidados de saúde e a diminuição dos tempos de internamento, por exemplo, têm trazido inúmeras dificuldades aos assistentes sociais, quer aumentando as barreiras ao acolhimento sistemático nos serviços, ao acompanhamento de "visitas clínicas" ou de decisões terapêuticas, quer exigindo respostas emergenciais sem possibilidade de uma planificação atempada e gestão da alta, quer potenciando 
respostas incompletas ou que se desatualizam a médio prazo. Tratam-se de processos complexos que ficam muito condicionados por uma afetação deficitária de recursos humanos como a que os resultados indicam.

Ainda que a nível hospitalar, nos serviços de internamento, a intervenção do Serviço Social vise a humanização e qualidade dos cuidados, a satisfação das necessidades dos doentes e suas famílias, contribuindo para a rentabilização dos serviços e recursos sociais e de saúde (LOPES et al., 2012), a afetação de recursos humanos no Serviço Social em cuidados hospitalares não segue um critério geral. Compreende-se a não aplicabilidade de uma norma unívoca para o staffing, atendendo à enorme disparidade entre os níveis e dimensões dos Hospitais ou mesmo entre Serviços ou Departamentos da mesma unidade hospitalar (APSS, 2017), o que torna complexa a discussão dos critérios para determinar a racionalidade pela sua ampla variabilidade.

Nalguns contextos a nível nacional e internacional são indicados rácios de assistentes sociais nos hospitais com base no número de camas, calculados a partir dos tempos despendidos e do movimento assistencial (tendo em consideração o número de casos acompanhados por unidade de saúde e o número de casos acompanhados pelo Serviço Social) ou do número de equipas de saúde. No contexto nacional, o referido documento de trabalho de 1979, na génese do SNS, divulgado pela APSS (GEPS, 1979), defendia a existência, nos hospitais distritais e centrais, de 1 profissional por cada 60 camas e de 1 profissional nas consultas externas por cada 25 doentes de primeira vez por dia. A nível internacional, por exemplo, nas Filipinas foi definido o rácio de 1 assistente social para cada 25 camas nos hospitais (NCHFD, 2013). Sabemos, no entanto, que não podemos basear a afetação de profissionais em regras lineares da aritmética, de forma descontextualizada, pois há serviços que necessitam de um apoio mais intensivo do Serviço Social do que outros, quer atendendo às características da população utente e complexidade da intervenção, quer atendendo ao número de equipas existentes.

Por isso, há áreas de especialidade que requerem critérios mais específicos e exigentes na definição de rácios, devendo estes refletir a acuidade, a complexidade e a natureza das necessidades específicas das populações-alvo dos serviços.

$\mathrm{Na}$ área da oncologia, a Association of Oncology Social Work (AOSW, Estados Unidos da América) (ZEBRACK, 2014) define uma fórmula orientadora para a determinação de afetação de número de casos (caseloads) e de cobertura do Serviço Social a ser calculada em cada instituição tendo em conta o movimento assistencial anual ${ }^{7}$.

$\mathrm{Na}$ área da saúde mental e psiquiatria, encontramos orientações de entidades nacionais para Portugal de 1 assistente social por equipa de saúde mental com 2 psiquiatras na comunidade e nos hospitais e instituições especializadas, ainda que a recomendação da OMS fosse de 1 assistente social para cada psiquiatra nos centros comunitários de saúde mental (sendo 1 psiquiatra para cada 25 mil habitantes) (GEPS, 1979). Na área da pediatria e saúde infantil, os níveis adequados de pessoal para o Serviço Social trabalhar com crianças, jovens e famílias, assegurando um número de de casos que permita intervenções efetivas seguem as seguintes diretrizes nos Estados Unidos da América de 1 assistente social por cada 25 camas de pediatria geral; 20 camas de cuidados intensivos; 15 camas de cuidados neonatais intensivos; 6 camas de pedopsiquiatria

\footnotetext{
${ }^{7}$ Para cálculo de "caseloads" parte do número de casos analíticos (isto é, os casos diagnosticados e/ou a receberem o primeiro ciclo de tratamento, completo ou incompleto, numa unidade por ano) e divide pelo número de profissionais efetivos a tempo integral, indicando assim o rácio adequado institucionalmente. No âmbito do ambulatório, são tidas em conta as vistas domiciliárias e os contactos com o Serviço Social efetuados divididos por profissionais a tempo integral para efeitos de calculo do racional, indicando assim a cobertura do Serviço Social segundo a AOSW (ZEBRACK, 2014).
} 
(APOSW, 2011). A mesma entidade exige assistentes sociais em apoio sistemático nos serviço de urgência (em regime de chamada nocturna) e determina também a necessidade de profissionais para apoio ao ambulatório para além dos referidos anteriormente na área pediátrica.

Em Portugal, as redes de referenciação hospitalar de psiquiatria e de saúde mental, assim como da área da psiquiatria da infância e da adolescência (MS, 2015; MS, 2018) sublinham os baixos rácios de recursos humanos na área de Serviço Social, agravando-se por serem profissionais partilhados com outros serviços "com um número de horas reduzido para desenvolver intervenções com crianças, adolescentes e suas famílias" (MS, 2018, p. 30). Nesta área verificou-se mesmo uma diminuição do número de assistentes sociais entre 2011 e 2016, "comprometendo a qualidade da intervenção no âmbito da Psiquiatria da Infância e da Adolescência", o que é contraditório com a ampla demonstração da "importância dos determinantes sociais na qualidade da saúde das populações, com impacto no âmbito da saúde mental" considerando-se neste documento ser fundamental que tenham assistentes sociais "alocados aos próprios serviços, e em número suficiente para poderem ser efetivos na sua ação" (MS, 2018, p. 30,41), sublinhando-se ainda que atualmente nesta área o rácio preconizado pela Direcção-Geral da Saúde (Circular Normativa n.․ 6/DSPSM, de 17/06/2005) era de 1/66.000 habitantes para os psicólogos, enfermeiros e assistentes sociais.

$\mathrm{Na}$ área da Reabilitação os assistentes sociais são também considerados membros essenciais na equipa multidisciplinar. Para os centros de reabilitação são indicados 2 assistentes sociais por cada 80 doentes internados e 40 em hospital de dia e 2 em cada equipa de reabilitação pediátrica (DSG, 2003).

Ainda que não tenha sido nosso objetivo esgotar a informação relativamente a todas as áreas, encontramos ainda, a nível nacional, legislação dispersa que insere assistentes sociais nas equipas multidisciplinares nalgumas áreas ou a adoção de recomendações internacionais em diferentes redes de referenciação que preconizam a fulcralidade destes recursos humanos.

Note-se que não dispomos de dados desagregados no presente estudo para poder discutir detalhadamente o racional nestas ou noutras áreas de especialidade. No entanto, coberturas populacionais e números de casos desproporcionados como aqueles que estimamos no presente estudo, assim como elevada pressão temporal são potenciadores de exaustão e burnout profissional. Para além disto, a tendente não renovação da categoria, assim como não substituição de assistentes sociais em situações de ausência prolongada ao serviço a nível hospitalar, pode traduzir-se em sobrecarga e em diminuição da qualidade da intervenção e dificultando o planeamento da alta, deixando doentes e famílias sem apoio (APSS, 2017).

$\mathrm{O}$ ambulatório é das áreas hospitalares em que se verifica geralmente menor cobertura por parte dos assistentes sociais em regime de acolhimento sistemático, optando-se frequentemente pelo regime de chamada que implica referenciação indireta pela equipa de saúde. No entanto, há especialidades em que o acompanhamento clínico é efetuado eminentemente através de consultas periódicas ou de tratamentos em ambulatório. Se atendermos à estimativa do número consultas anuais por cada assistente social nos hospitais do SNS (36.563), calculamos que haja 146 consultas por dia útil por cada assistente social, o que torna manifestamente impossível a implementação de processos sistemáticos de avaliação e de intervenção social qualificados. Lembramos que em 1979 se defendia o apoio às consultas externas de 1 profissional por cada 25 doentes de primeira vez por dia, verificando-se quase 6 vezes mais do que o desejável, ainda que os doentes possam ser de primeira vez ou de seguimento. Também nos parece que a desproporção existente impede a advocacia social a estes cidadãos, pois garantir a informação adequada acerca de direitos e acesso a recursos e a serviços, implica uma avaliação diagnóstica atenta. 
Assinale-se ainda que o apoio às unidades de hospital de dia e aos múltiplos serviços de consultas dentro de uma unidade hospitalar ocorre em acumulação com o apoio aos serviços de internamento e ao serviço de urgência. Uma das áreas em que o tratamento e acompanhamento se faz em ambulatório por excelência é a Nefrologia. Nesta área, o Conselho de Assistentes Sociais de Nefrologia dos Estados Unidos da América (CNSW, 1998) determina que deva existir, no mínimo, 1 profissional por cada 75 utentes, usando uma fórmula de cálculo que entra em linha de conta com fatores de risco psicossocial e as funções assumidas pelo Serviço Social ${ }^{8}$. Em Portugal, a legislação indica o assistente social como membro da equipa básica nas unidades de diálise ${ }^{9}$.

O trabalho em equipa multidisciplinar é fulcral nos processos e objetivos da intervenção do Serviço Social, mas a sua exequibilidade depende de rácios menos desequilibrados do que os existentes atualmente entre profissionais fundamentais nas unidades de saúde. Médicos e enfermeiros são sempre identificados como técnicos de saúde profissionais da carteira básica nos cuidados de saúde, sendo a desproporção assinalável, havendo cerca de 70 vezes mais enfermeiros e 50 vezes mais médicos do que assistentes sociais na área da saúde em Portugal.

Entre 2015 e 2017 aumentou ligeiramente o número de assistentes sociais (+0,04\%), de médicos $(+0,07 \%)$ e de enfermeiros $(+0,06 \%)$, tendo, consequentemente, melhorado o rácio por habitante para todas as profissões, no entanto, são as profissões com maior contingente que aumentam a um ritmo mais acelerado. Note-se que Portugal é o terceiro país da União Europeia com mais médicos (a seguir à Grécia e Áustria ), apresentando um rácio de 4,4 por cada 1000 habitantes, sendo a média dos 28 Estados-membros de 3,5; relativamente aos profissionais de enfermagem, Portugal é o 10. país com o rácio mais baixo, com apenas 6,1 enfermeiros por cada 1000 habitantes, sendo a média europeia de 8,4 (OECD; EC, 2016).

Em regra, "menos profissionais que o recomendado implica menor disponibilidade para praticar atos técnicos de saúde que potencialmente se traduzirão em maior morbilidade, mortalidade, reinternamentos, aumento da taxa de infeção, maiores tempos de espera e de listas de espera" (OPSS, 2017, p. 32). Ainda que a primazia do modelo biomédico esteja refletida nesta afirmação, se atendermos a uma conceção de saúde de acordo com os modelos biopsicossocial e holístico, estes atos de saúde estarão aquém dos objetivos se não incluírem outras dimensões que não apenas as somáticas no sentido de promover a perspetiva da pessoa como um todo e a intervenção nessa totalidade. A secundarização ou até a exclusão da participação de profissionais que trazem essas dimensões aos protocolos de intervenção das equipas na área da saúde traduz-lhe incompletude e desadequação.

Se estimarmos que $20 \%{ }^{10}$ das situações apresentadas pelos utentes que recorrem aos hospitais através da consulta, internamentos ou urgência necessitam de avaliação e de intervenção

\footnotetext{
${ }^{8}$ A fórmula usada pelo CNSW (1998) é a seguinte: Psychosocial Risk Factors x Patient Population Served During Year = Minimal Recommended Staffing Level Case Function Ratio. O nível de risco psicossocial é avaliado pela United States Renal Data Systems, sendo determinado o staff mínimo tendo por base funções reguladas em documentação (The Clinical Indicators for Social Work and Psychosocial Services in Nephrology Settings, National Association of Social Worker/ National Kidney Foundation, 1994).

${ }^{9}$ Decreto-Lei n. $.505 / 99$ de 20 de novembro, artigo 39.๑; Portaria n. 347/2013 de 28 de novembro, artigo 30.. (unidades privadas de diálise). $\mathrm{O}$ assistente social é reafirmado como membro da equipa básica das unidades de diálise e de diálise peritonial no Manual de Boas Práticas de Diálise Crónica da Ordem dos Médicos de 2017 com a seguinte afetação: 1 hora/ semana por cada 20 doentes tratados na unidade (p.57-58). A indicação da integração de pelo menos 1 assistente social nas equipas multidisciplares básicas também se verifica para as condultas de esclarecimento aos doentes com insuficiência renal crónico (estádio 5) nos serviços hospitalares de nefrologia (Circular normativa 17/2011 de 28/09 da DGS).
}

${ }^{10}$ Este percentual traduz apenas uma exemplificação. No entanto, apesar de termos um sistema universal e geral de saúde em 
social, teremos cerca de 7300 consultas, 430 internamentos e 2800 urgências para cada assistente social, isto é, cerca de 10500 ocorrências, no seu conjunto, em acompanhamento por assistente social. Mesmo se equacionarmos que apenas $10 \%$ dos casos (deste universo de $20 \%$ ) são efetivamente acompanhados, isto é, 2\% dos utentes nos diferentes episódios, teremos 1050 utentes por assistente social nos hospitais.

Não podem ser ignorados os indicadores preocupantes sobre a persistência nas barreiras de acesso a cuidados e à efetivação dos tratamentos entre as populações mais empobrecidas e com maiores limitações na literacia em saúde, já que Portugal apresenta a segunda taxa mais elevada entre os países da OCDE de população em situação de pobreza que abdica de tratamentos necessários por restrições económicos (OECD, 2019).

Entendemos a saúde numa perspetiva holística, considerando a ação do Serviço Social essencial na equipa multidisciplinar e não complementar, mas o racional atualmente existente, parece tornar manifestamente impossível alcançar níveis de participação em cuidados holísticos e de qualidade.

Apesar da evidência em torno da fulcralidade dos determinantes sociais e dos direitos humanos nas intervenções profissionais na área da saúde, continua a observar-se uma profunda desconexão e abordagens paradoxais nos cuidados prestados numa área da saúde ainda muito enraizada no modelo biomédico (PŪRAS, 2017). Os dados da morbilidade são também indicadores fundamentais para definir o racional profissional de forma adequada. É, assim, de ter por referência os dados relativos a doenças agudas e crónicas, assim como os índices de envelhecimento, de incapacidade e de dependência, com elevado impacte no bem-estar e na vida dos doentes, na família e na sociedade.

Os evidentes desafios para o sistema de saúde da transição demográfica e epidemiológica que vivemos de forma acelerada têm de ser atendidos numa dimensão multissetorial (DGS, 2015), mas também multiprofissional, de forma integrada e holística nos diferentes níveis de cuidados.

\section{CONCLUSÕES}

Analisados os dados sobre os assistentes sociais na área da saúde em Portugal e calculados os rácios em função de indicadores populacionais e regionais, dos níveis de cuidados, por tipo de entidade, e na relação com outros recursos humanos da equipa de saúde, são colocadas em evidência a relação desproporcionada a nível populacional e na relação com médicos e enfermeiros, assim como a desigual distribuição regional. Conclui-se, assim, pela evidente limitação de recursos humanos na área do Serviço Social, tanto nos cuidados de saúde primários como hospitalares no sentido de cumprir em pleno os seus objetivos de intervenção integrada e holística, de almejar uma participação efetiva e transversal nos diferentes níveis de cuidados e de favorecer a equidade dos cidadãos no acesso ao Serviço Social. O parco investimento no aumento de assistentes sociais neste sector de política social tem estagnado e motivado a falta de renovação e envelhecimento destes recursos humanos.

A inserção dos assistentes sociais na área da saúde deve enquadrar-se nos padrões de boas práticas e recomendações nacionais e internacionais, integrando equipas multiprofissionais. No entanto, o racional deve ser equilibrado, caso contrário, o trabalho em equipa não passará de

Portugal, e de o Serviço Social se dirigir a todos, independentemente da sua situação social, usamos este percentual tendo em consideração que a taxa de risco de pobreza em Portugal se aproxima desta percentagem, sendo que esta população apresenta potencialmente necessidades assistenciais acrescidas, atendendo aos determinantes sociais da saúde e da doença. 
mera retórica vazia. O modelo de planeamento de recursos humanos em saúde defendido pela ACSS (2017) que conta com a interação entre necessidades, objetivos e recursos em saúde e nos serviços está longe de ter concretização para o Serviço Social.

As limitações ao cumprimento dos desígnios profissionais são proporcionais às limitações de recursos humanos. Por isso, concordamos com a APSS quando considera fulcral o estabelecimento e cumprimento de rácios, devidamente ponderados, que contribuam de forma efetiva para a diminuição dos custos do sistema de saúde, "na medida em que a sua intervenção pode evitar reinternamentos, protelamento de altas, consumo excessivo de medicamentos e de procura dos serviços de urgência, ao propiciar recursos sociais que vão melhorar as condições de vida e bem estar dos utentes e famílias" (APSS, 2017, p. 23). Urge reforçar o investimento na capacidade de resposta do Serviço Social, incrementando a articulação com as famílias e serviços da comunidade, e potenciando ganhos globais em saúde para todos. Acresce ainda a necessidade de definição colegial de critérios de triagem e de referenciação, nos diferentes níveis de cuidados e áreas, para garantir a sua maior qualidade e efetividade, bem como de um sistema de informação que permita evidenciar os ganhos em saúde da população associados à intervenção do Serviço Social.

Sabemos que a definição dos rácios e de afetação adequada de assistentes sociais nas unidades de saúde se apresenta como extremamente complexa, porque complexos são também os processos de saúde e de doença e o sistema de cuidados que a sociedade organiza para lhes dar resposta.

Assim, a determinação do número de assistentes sociais adequados deve contemplar critérios e cruzar ponderadores de diversa natureza (APSS, 2017; LURIE, 1976; NASW, 2003):

- tipo, escopo e complexidade do programa de intervenção do Serviço Social nas unidades/estabelecimentos de saúde;

- o tipo, a dimensão e a complexidade de organização da unidade de saúde (o número de serviços, de departamentos e de equipas de saúde);

- o movimento assistencial da unidade de saúde e outros dados relativos à procura de cuidados e à produção das unidades de cuidados;

- as características da zona de abrangência;

- a população abrangida;

- a dispersão populacional e territorial;

- as características sociodemográficas e sociográficas da população utente;

- os dados epidemiológicos da população abrangida e utente (incidência e prevalência da morbilidade);

- as condições de vida e de trabalho da população abrangida;

- a complexidade das necessidades biopsicossociais da população utente;

- a diversidade e a complexidade das funções do Serviço Social e das atividades desenvolvidas pela equipa de saúde;

- o tempo previsto para a implementação das funções calculadas em unidades analíticas de caso ou em unidades populacionais;

- serviços, programas e projetos na comunidade com a participação do Serviço Social.

O número de atos profissionais envolvidos na intervenção social para garantir o acesso aos direitos, recursos e respostas sociais são geralmente proporcionais ao impacte que a doença tem na vida do doente, tanto no seu processo como no seu resultado. Acresce a exigência de 
humanização e de qualidade destes processos interventivos focados na salvaguarda e garantia da dignidade da pessoa humana. Não se trata, por isso, de uma racionalidade ponderada somente a partir de dados quantificáveis, exigindo-se que os critérios qualitativos nos cuidados de saúde sejam refletidos.

A nível dos cuidados primários, parece fundamental promover estudos que tracem um mapeamento das especificidades populacionais, a nível territorial, demográfico, epidemiológico e social. Tal dar-nos-ia uma visão mais aproximada da situação do país, permitindo sustentar propostas de afetação de recursos humanos com base em dados territorializados. No entanto, teremos de suplantar a dificuldade atribuída à falta de correspondência entre as 25 Unidades Territoriais NUTS III e as regiões de saúde subdivididas em $55 \mathrm{ACeS}$, que dificulta estudos de aprofundamento com base nos dados estatísticos disponíveis. Já a nível dos cuidados hospitalares, assim como em áreas específicas, serão também necessários estudos complementares para sustentar a definição de orientações claras para alcançar uma racionalidade adequada, que integrem designadamente a dimensão da unidade, a relação com as equipas de saúde existentes, os indicadores de produção da unidade, os níveis de complexidade associados aos processos de intervenção e os tempos despendidos nos processos de intervenção, que não se encontram definidos.

É agora evidente que o número de assistentes sociais na área da saúde no país e os rácios apresentados e analisados são incoerentes com as necessidades atuais do sistema de saúde português e comprometem futuras respostas de qualidade, caso se mantenha a tendência de subinvestimento neste grupo profissional. É necessário transformar a trajetória insatisfatória de inserção profissional na área da saúde num prólogo de novos capítulos de reconhecimento do papel fulcral do Serviço Social para uma área que coloque o cidadão e o seu direito à saúde holística no centro da sua atenção.

\section{Referências}

ACSS. Técnicos de Serviço Social no SNS/MS [Apresentação de 4 de abril de 2017]. Lisboa: Administração Central do Sistema de Saúde, IP, 2017.

APOSW. Standards for Social Work Care and Staffing in Pediatric Health Care Settings Prepared by The Society of Social Work Leadership in Health Care. Society for Social Work Leadership in Health Care Standards for Social Work Practice and Staffing in Children's Hospitals. 2011. Disponível em: http:// www.aposw.org/docs/sSWPedsStandards.pdf

APSS. Memorando sobre as e os Assistentes Sociais no Serviço Nacional de Saúde. Lisboa: Associação dos Profissionais de Serviço Social, 2017.

BRANCO, F.; FARÇADAS, M. O Serviço Social nos cuidados de saúde primários: contexto, perspetivas e desafios. In: CARVALHO, M. I. L. B. (coord.). Serviço Social na Saúde. Lisboa: Pactor, pp. 1-23, 2012.

BYWATERS, P.; NAPIER, L. Revising social work's international policy statement on health: process, outcomes and implications. Int Soc Work. 52, 4, 447-457, 2009.

CNSW. Position Statement on Social Work Staffing. Council of Nephrology Social Workers, 1998. Disponível em: https://www.kidney.org/sites/default/files/docs/staff_ratio.pdfhttp://www2.kidney. org/members/source/Custom/CNSW/pdf/CNSW-SOP_6thEd-FINAL_July2014.pdf

COWLES, L. A. F. Social work in the health field: A care perspective. 2. ed. New York: Routledge, 2012. doi:10.4324/9780203049884 
DAL-POZ, M.R.; KINFU, Y.; DRÄGER, S.; KUNJUMEN, T. Counting health workers: definitions, data, methods and global results. Department of Human Resources for Health, World Health Organization, 2007. Disponível em: http://www.who.int/hrh/documents/counting_health_workers.pdf

DGS. Rede de Referenciação Hospitalar de Medicina Física e de Reabilitação. Lisboa: Direcção-Geral da Saúde, Direção de Serviços de Planeamento, 2003. Disponível em: https://www.dgs.pt/upload/membro.id/ ficheiros/i006180.pdf

DGS. Direção de Serviços de Informação e análise. Centros de Saúde e Unidades Hospitalares: Recursos e produção do SNS 2011. Lisboa: Direção-Geral da Saúde (Portugal), 2014.

DGS. Saúde dos Portugueses: perspetiva 2015. Lisboa: Direção-Geral da Saúde (Portugal), 2015. Disponível em: https://www.dgs.pt/estatisticas-de-saude/estatisticas-de-saude/publicacoes/a-saudedos-portugueses-perspetiva-2015.aspx

GEPS. O Serviço Social no Sector da Saúde. Série de Documentos de Trabalho do Gabinete de Estudos e Planeamento da Secretaria de Estado da Saúde e da Assistência, Portugal, n. 2 [APSS, Cadernos n.ำ , 1979], 1979.

GUADALUPE, S.; GONÇALVES, A.M. Os números do serviço social nos cuidados de saúde primários: o caso da região centro de Portugal. Serviço Social \& Saúde, VII/VIII, 7-8, 127-160, 2009. doi: 10.20396/ sss.v7i1/2.8634934

GUADALUPE, S. Anotações cronológicas sobre a trajetória do serviço social no sistema de saúde em Portugal. Serviço Social \& Saúde, X, 12, 99-126, 2011. doi: 10.20396/sss.v10i2.8634831

GUADALUPE, S. A intervenção do serviço social na saúde com famílias e em redes de suporte social. In: CARVALHO, M. I. L. B. (coord.). Serviço Social na Saúde. Lisboa: Pactor, pp. 183-217, 2012.

LOPES, M. A.; RIBEIRO, A. R.; Espírito-SANTO, I.; FERREIRA, F.; FREDERICO, L. Serviço Social e qualidade em contexto hospitalar. In CARVALHO, M. I. L. B. (coord.). Serviço Social na Saúde. Lisboa: Pactor, pp. 25-53. 2012.

LURIE, A. Staffing patterns. Social Work in Health Care, 2:1, 85-94, 1976. doi: 10.1300/J010v02n01_10

MONDRAGÓN, J.; TRIGUEROS, O. Manual de prácticas de trabajo social en el campo de la salud. Madrid: Siglo XXI de España, 1999.

MS. Rede de referenciação hospitalar de psiquiatria e saúde mental. Ministério da Saúde, 2015. Disponível em: https://www.sns.gov.pt/wp-content/uploads/2016/05/redereferencia\%C3\%A7\%C3\%A3o-hospitalar-psiquiatria-e-sa\%C3\%BAde-mental.pdf

MS. Rede de referenciação hospitalar de psiquiatria da infância e da adolescência. Ministério da Saúde, 2018. Disponível em: https://www.sns.gov.pt/wp-content/uploads/2018/06/RRH-Psiquiatriada-Inf\%C3\%A2ncia-e-da-Adolesc\%C3\%AAncia-Para-CP.pdf

NASW. NASW Standards for Social Work services in long-term care facilites. National Association of Social Workers, 2003. Disponível em: https://www.socialworkers.org/LinkClick.aspx?fileticket=cw W7lzBfYxg\%3D\&portalid=0

NCHFD. Revised Organizational Structure and Staffing Standards for Government Hospitals. Filipinas: CY 2013 Edition, 2013. Disponível em: https://www.dbm.gov.ph/wp-content/uploads/ Issuances/2013/Joint\%20Circular\%202013/DOH/Manual\%20RSSGH_\%203\%20levels.pdf 
OECD; EC. Health at a Glance: Europe 2016 - State of Health in the EU Cycle. Organisation for Economic Co-operation and Development \& European Commission, 2016. Disponível em: http://www. oecd.org/health/health-at-a-glance-europe-23056088.htm

OECD. Health at a Glance 2019 - OECD indicators. Organisation for Economic Co-operation and Development, 2019. Disponível em: https://www.oecd-ilibrary.org/docserver/4dd50c09-en.pdf?expire S=1573558789\&id=id\&accname=guest\&checksum=D97619A4035E642A38989F 2710353379

OMS-CDSS. Redução das desigualdades no período de uma geração. Igualdade na saúde através da acção sobre os seus determinantes sociais. Relatório Final da Comissão para os Determinantes Sociais da Saúde. Portugal, Organização Mundial da Saúde, 2010. Disponível em: https://apps.who.int/ iris/bitstream/handle/10665/43943/9789248563706_por_contents.pdf;jsessionid=078E45EE18D700BA5 61F0B0D95A2D767? sequence $=8$

OPSS. Relatório Primavera 2017 - Viver em tempos incertos: sustentabilidade e equidade na saúde. Lisboa: Observatório Português dos Sistemas de Saúde, 2017. Disponível em: http://www.opss.pt/sites/ opss.pt/files/Relatorio_Primavera_2017.pdf

PŪRAS, D. Human rights and the practice of medicine. Public Health Rev., 38, 9, 2017. doi: 10.1186/ s40985-017-0054-7

RUTH, B. J.; MARSHALL, J. W. A History of Social Work in Public Health. American journal of public health, 107, S3, S236-S242, 2017. doi:10.2105/AJPH.2017.304005

SANTANA, P. Introdução à geografia da saúde: território, saúde e bem-estar. Coimbra: Coimbra University Press, 2014.

SNS. Circular Normativa N.1/2017/CNCP/ACSS de 12-01-2017 para: Instituições Hospitalares do SNS, Administrações Regionais de Saúde, IP/Agrupamentos de Centros de Saúde/Unidades Locais de Saúde, EPE, Ministério da Saúde, Portugal, 2017. Disponível em: http://www.acss.min-saude.pt/wp-content/ uploads/2016/11/Circular-Normativa_1_2017.pdf

WHO. Health Workers. In The World Health Report (pp.1-17). World Health Organization, 2006. Disponível em: http://www.who.int/whr/2006/06_chap1_en.pdf

WHO. World conference on social determinants of health: meeting report, Rio de Janeiro, Brazil, 19-21 October 2011. World Health Organization, 2012. Disponível em: https://www.who.int/sdhconference/ resources/Conference_Report.pdf?ua=1

ZEBRACK, B. Guidance for Determining Oncology Social Work Staffing Standards. AOSW, 2014. Disponível em: https://www.aosw.org/AOSW/media/Main-Site-Files/Projects\%20and\%20 Partnerships/Documents/August15ResearchCommitteereportREVdwr_1.pdf 